DOI $10.18307 / 2015.0503$

(C) 2015 by Journal of Lake Sciences

\title{
基于浓缩法的浮游植物定量数据稳定性与可靠性分析”
}

\author{
牛海玉 ${ }^{1}$, 陈 纯 ${ }^{1}$, 韩博平 ${ }^{1,2 * *}$ \\ ( 1 : 暨南大学生态学系,广州 510632$)$ \\ (2:广东省水库蓝藻水华防治中心,广州 510632)
}

\begin{abstract}
摘 要: 浮游植物是水生生态系统中重要的初级生产者, 相对准确地定量它们的数量是进一步进行水质评价和生态功能 分析的基础. 通过采集处于不同营养状态的水库和不同处理的围隔中的浮游植物, 研究影响浓缩法定量浮游植物的因 素, 了解如何通过浓缩法来合理地定量浮游植物. 分析浓缩倍数、样品的显微镜计数量、水体营养状态对浮游植物丰度、 生物量及群落多样性等定量参数稳定性的影响, 同时比较单个不同水体中重复 (或平行) 样品之间浮游植物丰度的差别. 结果表明, 基于浮游植物的显微镜计数效率与定量数据稳定性的综合考虑, 选择计数 4 片 $\times 10$ 格/片即可基本保证定量 数据的稳定性; 在保证正常镜检的基础上, 考虑水体营养状态适当增加浓缩倍数能够提高定量数据的可靠性; 在特别依 赖生物量或稀有种进行水质评价时, 处于不同营养水平的水体均需要增加样品的平行数来提高定量数据的可靠性.
\end{abstract}

关键词: 浮游植物; 计数; 丰度; 生物量; 多样性; 浓缩法

\section{Quality and reliability of quantifying phytoplankton abundance and biomass data based upon the concentrated water sample method}

\author{
NIU Haiyu ${ }^{1}$, CHEN Chun $^{1} \&$ HAN Boping ${ }^{1,2}$ \\ (1: Department of Ecology, Jinan University, Guangzhou 510632, P. R. China) \\ (2: Guangdong Center for Protection and Control of Cyanobacterial Blooms in Reservoirs, Guangzhou 510632, P. R. China)
}

Abstract: Phytoplankton is a main primary producer, especially in pelagic ecosystems. Thus it needs to be well quantified for measuring its function and assessing water quality. To explore data quality of phytoplankton by the concentrated water sample method which has been widely applied in China and other developing countries, phytoplankton samples were collected from three reservoirs with distinct trophic levels and three treatment groups of experimental enclosures. The potential effects of the concentration ratios of water samples, counting volumes, replicates of water samples on the data quality were statistically analyzed. To balance the stability of data and counting efficiency under microscopy, we recommend to count 4 plates $\times 10$ lattices for each plate. In the range of clearly and easily counting, increasing the concentration ratios of the water samples can improve precision and reliability of the quantitative data. When collecting multiple samples for counting is possible, especially those used for assessing the water quality, replicates of water samples are strongly recommended to be collected in order to reduce the standard deviation.

Keywords: Phytoplankton; counting; abundance; biomass; diversity of species; concentrated water sample method

浮游植物是水域生态系统中的重要初级生产者, 能快速响应水体水质和营养状态的变化, 其种类和数 量信息被广泛应用于水质和富营养化的监测、评价以及风险预警 ${ }^{[1-3]}$. 浮游植物现存量是指某一时间内单位 体积水体中所存在的浮游植物数量, 即浮游植物丰度 (密度) 或浮游植物的生物量 ${ }^{[4]}$. 尽管计数是定量浮游 植物的关键环节, 但如何提供较为可靠的浮游植物定量数据仍然困扰着初学者甚至长期从事浮游植物监测 的人员.

在浮游植物定量过程中, 采集一定体积的水样, 加固定剂后, 再将水样浓缩后利用显微镜进行计数, 然

* 国家重点基础研究发展计划“973”项目(2012CB956104) 和广东省水利科技创新项目 (201102) 联合资助. 2014 - $10-$ 11 收稿;2014-12-28 收修改稿. 牛海玉 (1990 ), 女, 硕士研究生;E-mail: niuniu-nhy@ 163. com.

** 通信作者;E-mail: tbphan@jnu. edu.cn. 
后根据浮游植物细胞的形态按最近似的几何形态测量必要的量度, 计算出浮游植物的体积, 通过比重转化 为生物量 ${ }^{[5-6]}$. 浮游植物的个体和细胞大小相差很大, 生物量被认为更能反映浮游植物群落在生态系统中的 作用, 但从样品采集到最后的生物量计算的每个环节均会产生误差. 陈纯等分析了浮游植物定量过程中生 物量计算可能产生的误差 ${ }^{[7]}$. Zarauz 等比较分析了活体样品与加固定剂样品在生物量上的差别 ${ }^{[8]}$. 在浮游 植物计数的样品处理上, 通常采用 2 种方法, 即样品浓缩法和沉淀杯法 ${ }^{[9]}$. 样品浓缩法是将水样通过毛细管 进行浓缩再进行显微镜计数的方法. 理论上, 当浓缩损失很小且具有足够的数量进行显微镜计数时, 浓缩法 可提供较好的数据质量. 然而, 浓缩过程耗时且存在细胞损失, 同时计数量也因样品性质和镜检人员而 异 ${ }^{[10]}$. 自 1978 年联合国教科文组织将 Utermöhl 计数法编人浮游植物手册以来,已成为目前国际上浮游植物 调查研究最通用的方法 ${ }^{[11]}$. 该方法需要采用倒置显微镜和特定的沉淀杯, 从而限制了发展中国家的使 用 ${ }^{[1-1-14]}$. 目前多数发展中国家仍然广泛采用样品浓缩法, 我国湖泊等监测标准也推荐样品浓缩法 ${ }^{[15-16]}$. 在实 际的操作上, 浓缩法存在很大的经验性, 如浓缩倍数和重复计数的片数或视野数并没有明确的规定, 导致不 同人员在计算时采用的质量控制是不同的,从而降低了不同来源数据之间的可比性 ${ }^{[16]}$. 因此,认识基于浓缩 法的浮游植物定量数据的影响因素仍非常必要.

浓缩法计数是将一定体积 $(0.1 \mathrm{ml})$ 的待测浮游植物浓缩样品置于具有确定面积和容积的载玻片一 浮游植物计数板上, 在显微镜下直接计数的一种方法 ${ }^{[15]}$. 国内规范中的浓缩法计数有两种标准, 一种为在 $10 \times 40$ 倍镜下, 每片对 $2 、 5 、 8$ 列进行计数, 每瓶标本计数 2 次 ( 2 片) 取平均值 ${ }^{[16]}$; 另一种方法为在 $10 \times 40$ 倍镜下最少计数 100 个视野, 每瓶标本计数 2 次 (2 片) 取平均值 ${ }^{[5]}$. 每片计数的 100 个视野要保证均匀分布 在计数框中. 浮游植物丰度低的情况下, 需要增加计数的视野数 (100 500 个), 以保证在计数视野数中浮游 植物个体的总数达到 100 个以上. 在计数过程中, 如碰到某些个体部分在视野中、部分在视野外时, 可只对 出现在视野上半圈的浮游植物计数, 而出现在下半圈的浮游植物不计数, 如全部计数会导致定量结果偏 高 ${ }^{[5]}$. 本文采用 $10 \times 10$ 倍镜对整片的体积较大的浮游植物 (大于 $15 \mu \mathrm{m}$ ) 进行计数, 在 $10 \times 40$ 倍镜下随机选 取 4 列对较小的浮游植物 $(2 \sim 15 \mu \mathrm{m})$ 进行计数的方法.

本研究的水样采集于 3 座不同营养水平水库的敞水区以及 3 种不同处理的实验围隔,这些样品提供了 多样化的浮游植物群落. 本文的结果和结论可为仍采用浓缩法的人员和实验室了解和掌握该方法的特点及 提高数据可靠性提供依据.

\section{1 材料与方法}

\section{1 采样地点与采样方法}

浮游植物定量样品采集于 3 座不同营养水平的大型水库及 3 组不同处理的实验围隔. 3 座水库分别为 流溪河水库 (贫中营养)、高州水库 (中营养) 和大沙河水库 (富营养) ${ }^{[17]}$. 实验围隔 3 组处理分别为添加营养 盐组、添加鱼类组和对照组,每个处理组均设置 5 个平行, 每个围隔的体积为 $90 \mathrm{~m}^{3[18]}$.

于 2013 年 5 月对 3 座水库进行一次性定量分析样品的采集, 同时测定水体的相关理化指标及叶绿素 a 浓度 ${ }^{[19]} .3$ 座水库浮游植物定量分析样品用采水器在各水库的敞水区水体表层 $0.5 \mathrm{~m}$ 处采得, 采集水样的 体积为 $10 \mathrm{~L}$, 混合均匀后分装至 5 个 $1 \mathrm{~L}$ 聚乙烯塑料瓶中, 并以终体积比为 $5 \%$ 的福尔马林固定, 以待下一步 的浓缩和镜检. 2013 年 7 月对 15 个围隔进行一次性采样, 每个围隔在水体表层 $0.5 \mathrm{~m}$ 处采集 $1 \mathrm{~L}$ 水样, 并以 终体积比为 5\% 的福尔马林固定, 以待下一步的浓缩和镜检 ${ }^{[16-17]}$.

\section{2 样品处理及计数方法}

水库和围隔的水样处理和计数方法一致. 将样品静置一周后用孔径为 $20 \mu \mathrm{m}$ 的多层筛绢封盖的直径为 $2 \mathrm{~mm}$ 的虹吸管吸出上层清液 ${ }^{[20]}$, 根据水库的营养水平, 将流溪河水库的样品浓缩到 $15 \mathrm{ml}$, 高州水库、大沙 河水库样品浓缩到 $50 \mathrm{ml}$, 围隔样品均浓缩到 $30 \sim 50 \mathrm{ml}$.

将待鉴定浮游植物样品充分摇勺后用移液枪吸取 $0.1 \mathrm{ml}$ 置于 $0.1 \mathrm{ml}$ 浮游植物计数框 (共 100 格) 中, 使用 Olympus BX51 显微镜进行镜检, 在 $10 \times 10$ 倍镜下对体积较大的浮游植物 (大于 $15 \mu \mathrm{m}$ ) 进行整片计数, $10 \times 40$ 倍镜下对较小的浮游植物 $(2 \sim 15 \mu \mathrm{m})$ 在一定视野下 $\left(10\right.$ 格/片) 进行计数 ${ }^{[21]}$. 每片的定量结果代表 用上述方法对 $0.1 \mathrm{ml}$ 的浓缩水样进行镜检计数后计算所得的浮游植物数量. 每个浮游植物样品分别镜检 5 
片 (每片计数 10 格). 分别从 5 片中随机选择其中 $1 、 2 、 3 、 4$ 片的计数总量累加后换算成相应的浮游植物细 胞丰度.

\section{3 浮游植物的鉴定、计数及群落丰度和生物量的计算}

浮游植物种类鉴定主要参照有关文献的描述及图鉴 ${ }^{[22]}$.

基于浓缩法, 每个样品分别镜检 5 片浮游植物样品, 并分别计算镜检每片样品所对应的丰度及生物量:

$$
N=\frac{A \cdot V_{\mathrm{s}} \cdot n}{A_{\mathrm{c}} \cdot V_{\mathrm{a}}}
$$

式中, $N$ 为浮游植物丰度 $(\mathrm{cells} / \mathrm{ml}) ; A$ 为计数框面积 $\left(\mathrm{mm}^{2}\right) ; A_{\mathrm{c}}$ 为计数面积 $\left(\mathrm{mm}^{2}\right) ; V_{\mathrm{s}}$ 为 $1 \mathrm{~L}$ 原水样沉淀浓缩 后的体积 $(\mathrm{ml}) ; V_{\mathrm{a}}$ 为计数框的容积 $(0.1 \mathrm{ml}) ; n$ 为计数所得的浮游植物数量 $(\text { cells })^{[23-24]}$.

使用光学显微镜对定量样品进行细胞计数和体积测量后, 根据体积公式计算单个种类的体积和生物量 (藻细胞湿重) $)^{[25]}$.

\section{4 群落丰度、群落生物量、浮游植物种类数的随机抽取及计算}

采用随机化方法 (bootstrapping), 从计数的 5 片中随机抽取 $1 、 2 、 3 、 4$ 片计算群落丰度、生物量、辛普森多 样性指数 ${ }^{[26]}$, 同时计算出各定量指标所对应的偏差. 采用随机化方法, 提供各定量指标的均值和偏差. 同时, 采用群落多样性稀疏方法 ( rarefaction), 对不同平行样品所代表的群落结构进行比较. 所有计算在 R 语言中 实现 ${ }^{[27]}$.

\section{2 结果与分析}

\section{1 浮游植物群落种类组成}

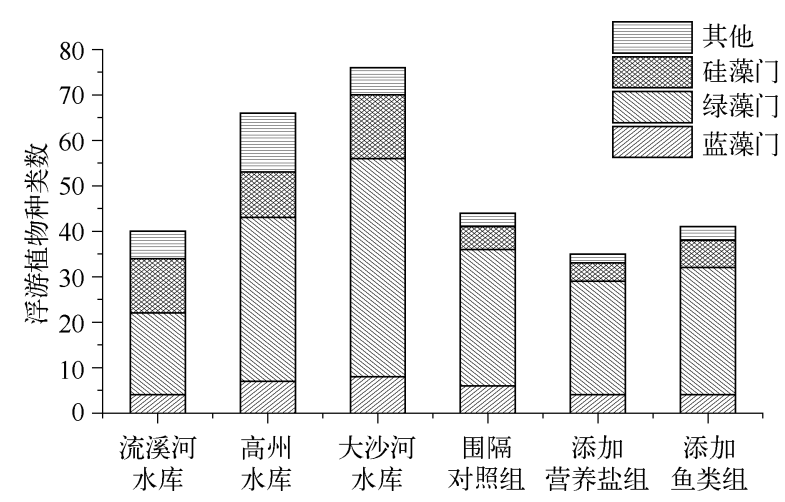

图 1 浮游植物种类数及其群落组成

Fig. 1 Species richness and composition of phytoplankton communities
在所采集的浮游植物样品中, 流溪河水 库共鉴定出 6 门 40 种, 高州水库 5 门 56 种, 大沙河水库 7 门 76 种. 围隔的对照组 6 门 44 种, 添加营养盐组 5 门 35 种, 添加鱼类组 5 门 42 种 (图 1).

\section{2 不同计数量的浮游植物丰度、生物量与}

种类数

根据对计数量为随机化抽取的 $1 、 2 、 3 、 4$ 片与全部 5 片定量数据的比较, 浮游植物丰 度随着计数片数的增加趋于稳定, 偏差减小 (图 2a). 4 片的生物量数据基本趋于稳定, 且相对 $1 、 2 、 3$ 片平行所得数据偏差较小 (图 $2 b)$. 计数片数与浮游植物种类数偏差呈负 相关, 随计数片数的增加, 浮游植物种类数偏 差减小 (图 2c).

\section{3 平行水样浮游植物定量的重复性}

根据 2.2 节数据分析, 选择在计数 4 片的计数量下进行平行水样定量数据的比较, 3 座水库的 5 个平行 样品之间的丰度、生物量和辛普森指数都有较大差别 (图 3). 单个 (瓶) 浮游植物样品的丰度与 5 个 (瓶) 浮 游植物样品的平均丰度之间最大相差为 $33.14 \%$; 单个 (瓶) 浮游植物样品的生物量与 5 个 (瓶) 浮游植物样 品的平均生物量之间最大相差 $45.28 \%$; 浮游植物群落辛普森指数最大相差 $54.19 \%$.

3 座水库各自 5 个平行样品的浮游植物群落种类稀疏曲线提供不同样品所对应群落结构的比较 (图 4). 由于样品计数量的随机性, 对单个水库而言, 每个平行样品的总计数细胞数存在差异, 观测到的浮游植 物种类数不同. 营养水平较高的大沙河水库和高州水库中观测到的种类数基本达到稳定, 而营养水平较低 的流溪河水库中所观测到的种类数没有达到渐近线. 

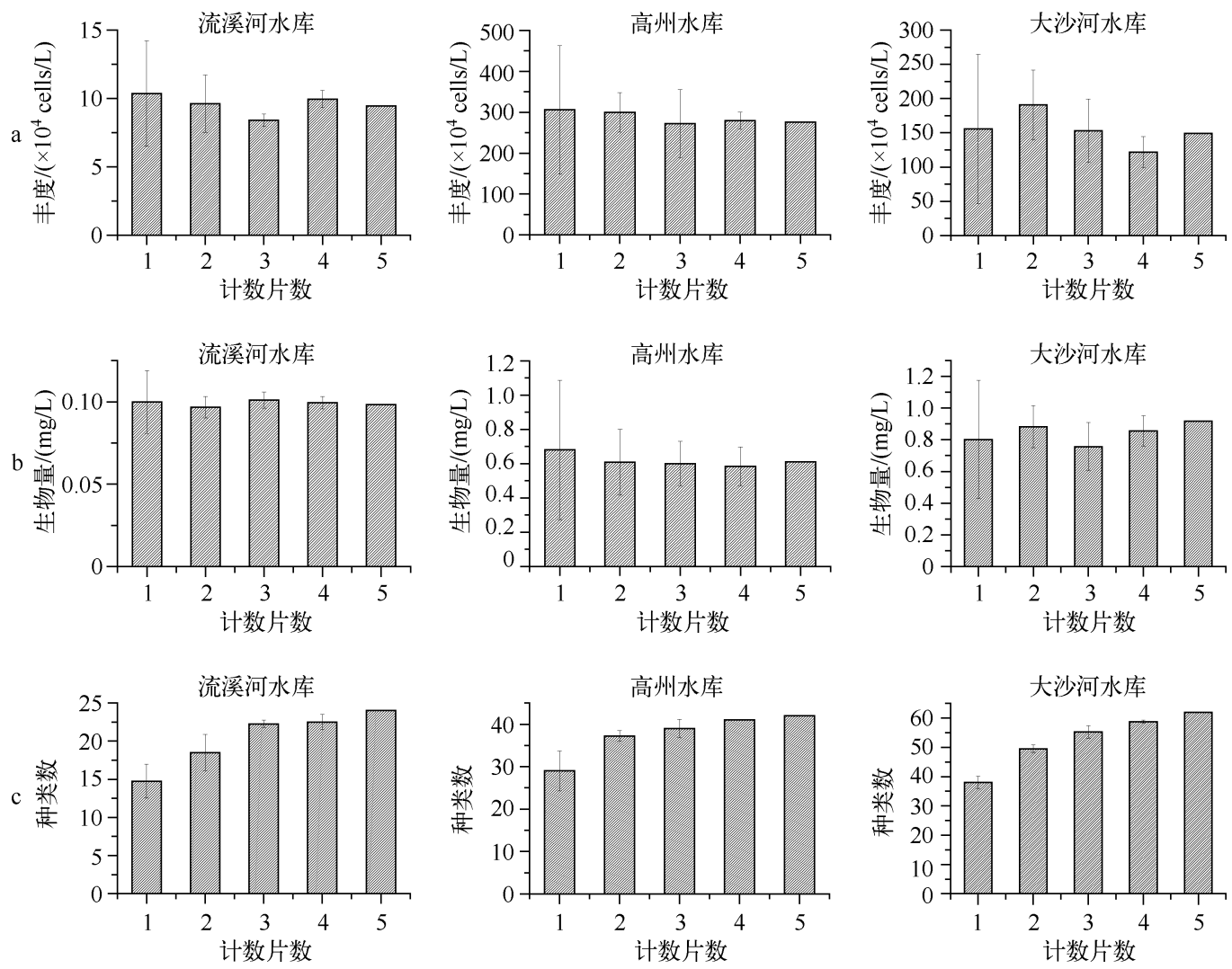

图 2 不同计数量下浮游植物丰度 $(\mathrm{a})$ 、生物量 $(\mathrm{b})$ 和种类数 $(\mathrm{c})$ 的比较

Fig. 2 Comparison of abundance(a), biomass(b), and species richness (c) of phytoplankton under different counting volumes

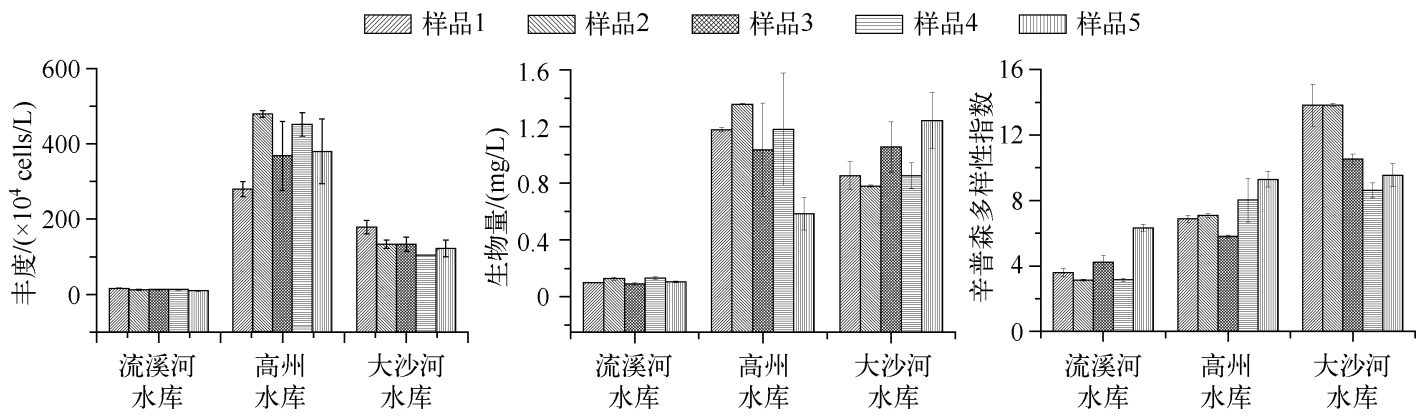

图 33 座水库的 5 个平行样品中每个样品计数 $4 \times 10$ 格下的浮游植物丰度、生物量和辛普森多样性指数

Fig. 3 Abundance, biomass and Simpson index of phytoplankton in five repeated water samples from three reservoirs under counting $4 \times 10$ lattices

\section{4 浓缩倍数、丰度、生物量与数据质量}

对计数 4 片 (每片 10 格) 的浮游植物定量数据进行偏差分析, 以了解浓缩倍数、浮游植物总丰度、 浮游植物总生物量对定量数据偏差的影响. 浓缩倍数与丰度偏差呈显著相关 (图 $5 \mathrm{a}$ ), 说明浓缩倍数显 著影响浮游植物群落丰度定量数据的稳定性. 浓缩倍数与生物量偏差的相关性不显著 $(P=0.109)$, 说 

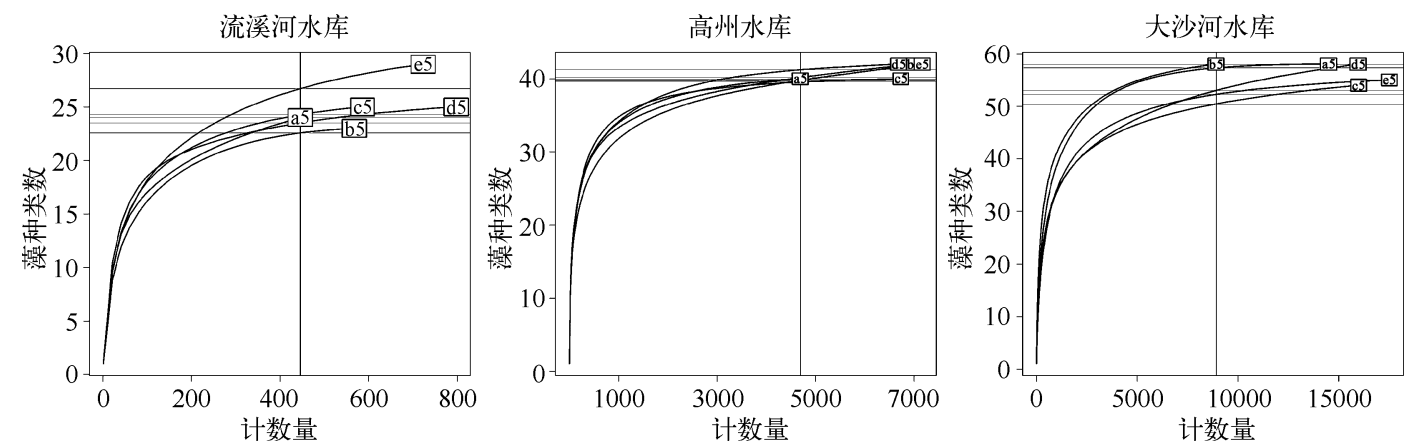

图 43 座水库 5 个平行样品中浮游植物群落的种类稀疏曲线

Fig. 4 Rarefaction curves of species richness in five repeated water samples from three reservoirs at distinct trophic states

明浓缩倍数对生物量稳定性的影响相对较弱. 浮游植物总丰度与丰度偏差、生物量偏差之间均呈显著 相关 ( 图 $5 \mathrm{~b} 、 \mathrm{c}$ ), 说明水体浮游植物总丰度对丰度、生物量定量数据的稳定性都有显著影响, 总丰度越高, 丰度、生物量的定量数据稳定性越低. 浮游植物总生物量与生物量偏差呈显著正相关 (图 $5 \mathrm{~d}$ ), 说明浮游 植物总生物量越高, 生物量定量数据的稳定性越低. 浮游植物总生物量与丰度偏差的相关性不显著 $(P=$ $0.521)$.
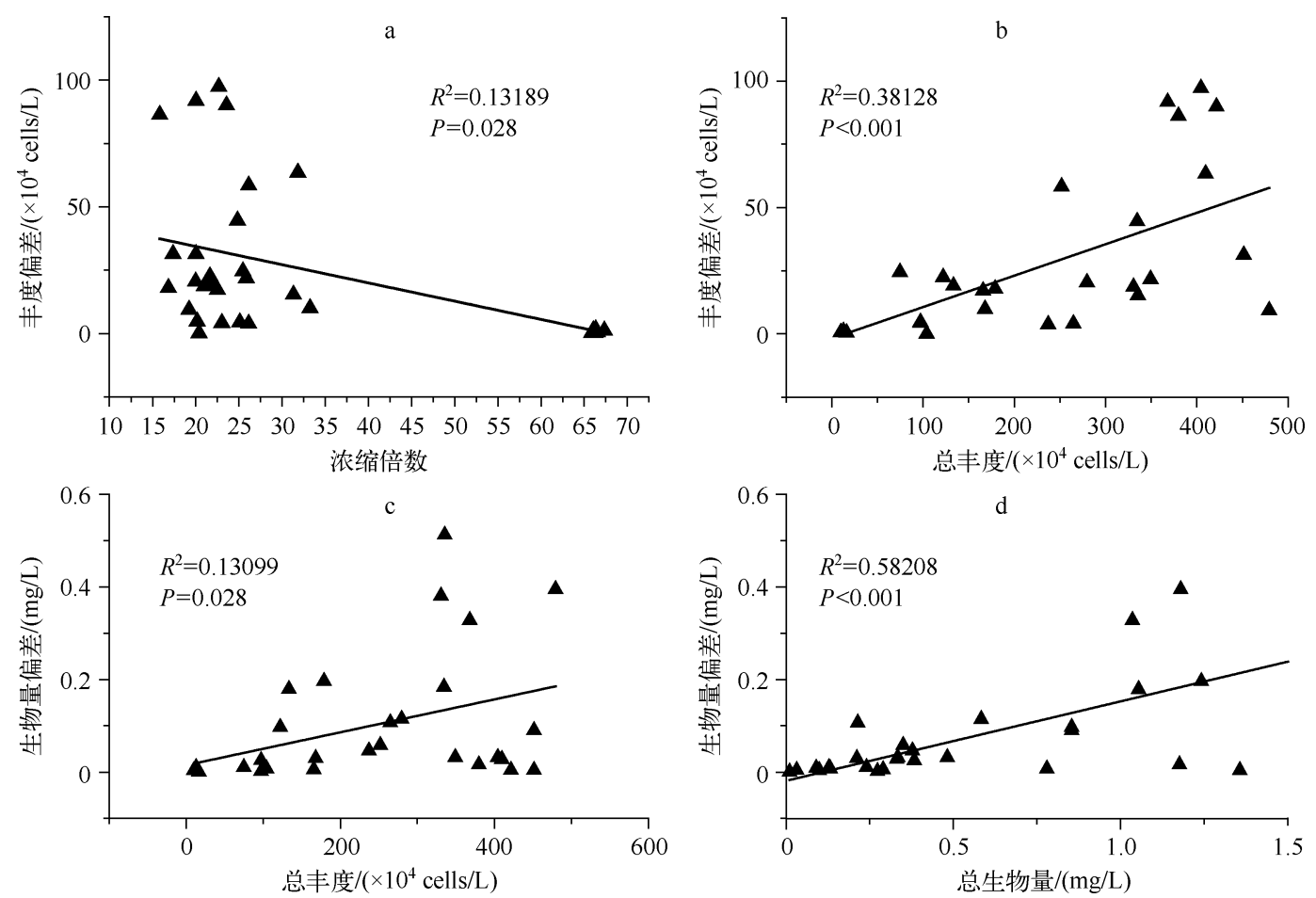

图 5 浓缩倍数、浮游植物总丰度、浮游植物总生物量与丰度偏差、生物量偏差间的相关性

Fig. 5 Correlations between data quality (standard deviation) and the counted concentration ratio of samples, total counting abundance and biomass of phytoplankton 


\section{3 讨论}

\section{1 计数量对浮游植物丰度、生物量与群落多样性的影响}

浓缩法的计数量控制有两类:一种是在 $10 \times 40$ 倍镜下, 每片镜检 $2 、 5 、 8$ 列并进行记录, 看 2 片平行样 品 ${ }^{[16]}$; 另一种方法是在 $10 \times 40$ 倍镜下镜检 $100 \sim 500$ 个视野 ${ }^{[5]}$. 也有研究采用计数大于 300 个细胞即可停 止的方法 ${ }^{[21]}$. 本文采用的是 $10 \times 10$ 倍下镜检整片浮游植物计数板、10 $\times 40$ 倍镜下随机镜检 4 列 (每片计数 100 格中的 10 格, 计数 4 片) 的方法. $10 \times 10$ 倍镜下镜检整片浮游植物计数框可以减少大个体浮游植物及稀 有种无法被镜检的概率, 稀有种对定量结果影响较大, 因此 $10 \times 10$ 倍下镜检整片浮游植物计数是非常必 要的 ${ }^{[7,29]}$.

随计数量的增加, 浮游植物丰度偏差、生物量偏差均减小, 并且随计数量增加镜检到的浮游植物种类数 增加. 所以增加镜检计数的片数可提高定量结果可信度. 本文数据分析表明, 计数 4 片 (每片 10 格) 即可使 丰度、生物量的偏差较小, 从而保证数据的稳定性和可靠性. 因浮游植物计数框盖玻片没有密封性, 样品中 水分蒸发会导致计数不准确, 因此计数过程应尽快完成 ${ }^{[8]}$. 随机镜检 4 列既保证了镜检的随机性又能够减 少记录视野数的工作量, 可缩短镜检时间, 避免样品中水分蒸发过多而影响定量结果的准确性, 并提高镜检 效率. 综合考虑效率和数据可靠性, 浮游植物定量中每个样品镜检 4 个平行时定量数据基本稳定, 但建议每 个浓缩后的样品计数 5 片 (每片 10 格), 从 5 片中随机抽取 4 片可以提供 4 片下的均值和偏差, 从而可了解 数据的置信区, 能够为数据质量控制提供有价值的参考. 特别是对以往没有采样经历的水体, 可采用这种方 法来确定计数量.

\section{2 平行样品数与浮游植物定量偏差的关系}

浮游植物总丰度、总生物量也是影响丰度和生物量定量偏差的重要因素,总丰度和总生物量的提高会 增加这类偏差, 说明浮游植物丰度越高的水体单一样品计数计算出的浮游植物定量数据不稳定可能性越 高. 稀疏曲线提供了分析和比较不同样品群落结构的方法,这种方法在开展多样性分析时更为有效. 导致平行 样品定量数据之间的差别,一方面与水样之间的可重复性有关,另一方面也与浓缩过程的可重复性有关. 为提 高浮游植物定量数据的可靠性,在条件允许的情况下采集平行样品是必要的,特别是当水体处于某一个水质 等级附近时,更需要以平行水样来保证数据质量和评价结果的可靠性.

\section{3 浓缩倍数与丰度偏差、生物量偏差的关系}

样品浓缩倍数与浮游植物定量数据的偏差有显著相关性, 在一定范围内浮游植物定量结果偏差随浮游 植物样品浓缩倍数的增加而降低. 浓缩倍数与生物量偏差的这种关系, 说明在水体营养水平较低时, 浓缩倍 数越大则浮游植物群落定量结果的稳定性越高. 增加浓缩倍数可增加计数的细胞数量和稀有种被镜检到的 概率, 从而提高定量结果的可信度. 需要指出的是, 本文中高浓缩倍数的数据点较少.

我国已发表的论文目前仍主要采用浓缩法定量浮游植物, 根据规范一般浓缩到 $30 \mathrm{ml}^{[16]}$. 但对富营养化 水体而言, 浮游植物丰度增加, 水体浓缩到 $30 \mathrm{ml}$ 导致镜检过程中视野中浮游植物可能会存在重叠或丰度过 大无法计数的现象. 因此, 浓缩体积应考虑到待检水体的营养水平, 因此建议寡营养水平水体 (如流溪河水 库) 浓缩到 $15 \sim 20 \mathrm{ml}$, 中营养水平水体 (如高州水库) 浓缩到 $40 \sim 50 \mathrm{ml}$, 富营养水平水体(如大沙河水库) 浓 缩到 $70 \sim 80 \mathrm{ml}$.

\section{4 结论}

1) 浓缩法计数通过增加计数量可提高定量数据的稳定性,4 片(每片 10 格)基本稳定. 我们建议共计数 5 片, 从 5 片中随机抽取 4 片可以提供 4 片下的均值和偏差, 从而了解数据的置信区, 为数据质量控制提供参考.

2) 由于定量数据偏差受水样本身和浓缩中虹吸过程的影响,在条件可能或水质评价等要求时,应采集 平行 (重复) 样品来降低偏差.

3) 浮游植物样品的浓缩体积要根据水体的营养水平及浮游植物丰度而定,在不影响镜检计数可行性的条件 下增加浓缩倍数可提高定量数据的精确性. 建议体积为 $1 \mathrm{~L}$ 的浮游植物样品, 葟营养水平水体浓缩到 $15 \sim$ $20 \mathrm{ml}$, 中营养水平水体浓缩到 $40 \sim 50 \mathrm{ml}$, 富营养水平水体浓缩到 $70 \sim 80 \mathrm{ml}$. 


\section{5 参考文献}

[ 1 ] Bianchi F, Acri F, Aubry FB et al. Can plankton communities be considered as bio-indicators of water quality in the Lagoon of Venice? Marine Pollution Bulletin, 2003, 46: 964-971.

[ 2 ] Reynolds CS. Ecology of plankton. Cambridge: Cambridge University Press, 2006.

[ 3 ] Richardson TL, Gibson CE, Heaney SI et al. Temperature, growth and seasonal succession of phytoplankton Lake Baikal, Siberia. Freshwater Biology, 2000, 44 : 431-440.

[ 4 ] Hallegraeff GM. A comparison of different methods used for the quantitative evaluation of biomass of freshwater phytoplankton. Hydrobiologia , 1977, 55(2) : 145-165.

[ 5 ] 王 冀,王 建. 浮游植物的采集、计数与定量方法. 水库渔业, 1982,4:58-63.

[6] 杜胜蓝, 黄岁樑, 藏常娟等. 浮游植物现存量表征指标间相关性研究 I : 叶绿素 a 与生物量. 水资源与水工程学报, $2011,22(1): 40-44$.

[ 7 ] 陈 纯,李思嘉,胡 韧等. 四种浮游植物生物量计算方法的比较分析. 湖泊科学,2013,25(6):927-935. DOI 10. 18307/2013.0617.

[ 8 ] Zarauz L, Irigoien X. Effects of Lugol's fixation on the size structure of natural nano-microplankton samples, analyzed by means of an automatic counting method. Journal of Plankton Research, 2008, 30 (11) : 1297-1303.

[ 9 ] Bollmann J, Cortés MY, Haidar AT et al. Techniques for quantitative analyses of calcareous marine phytoplankton. Marine Micropaleontology, 2002, 44(3) : 163-185.

[10］金相灿,屠清瑛. 湖泊富营养化调查规范:第 2 版. 北京:中国环境科学出版社, 1990:239-245.

[11] Lund JWG, Kipling C, Le Cren ED. The inverted microscope method of estimating algal numbers and the statistical basis of estimations by counting. Hydrobiologia, 1958, 11(2): 143-170.

[12] Hamilton PB, Proulx M, Earle C. Enumerating phytoplankton with an upright compound microscope using a modified settling chamber. Hydrobiologia, 2001, 444(1/2/3): 171-175.

[13 ] Rott E, Salmaso N, Hoehn E. Quality control of Utermöhl-based phytoplankton counting and biovolume estimates-an easy task or a Gordian knot? Hydrobiologia, 2007, 578(1) : 141-146.

[14] 孙 军, 刘东艳, 钱树本. 一种海洋浮游植物定量研究分析方法一Utermöhl 方法的介绍及其改进. 海洋科学进 展, $2002, \mathbf{2 0}(2): 105-112$.

[15] 陈 坤, 张前前, 史海燕等. 浮游植物计数方法比较研究. 海洋环境科学, 2007,26(4) : 383-385.

[16］章宗涉,黄祥飞. 淡水浮游生物调查规范. 北京:科学出版社,1991:339-344.

[17] 林秋奇, 胡 韧, 段舜山等. 广东省大中型供水水库营养现状及浮游生物的响应. 生态学报, 2003, 23 (6) : 1102-1108.

[18] 陈晓玲, 程 丹, 李慧明等. 南亚热带水库中盔形溞牧食对浮游植物群落影响的围隔试验. 水生态学杂志, 2012,33 (3) :20-26.

[19] 林少君,贺立静,黄沛生等. 浮游植物中叶绿素 a 提取方法的比较与改进. 生态科学,2005,24(1):9-11.

[20] Hu R, Han BP, Naselli-Flores L. Comparing biological classifications of freshwater phytoplankton: a case study from South China. Hydrobiologia, 2013, 701(1) : 219-233.

[21] Zhou G, Zhao X, Bi Y et al. Phytoplankton variation and its relationship with the environment in Xiangxi Bay in spring after damming of the Three-Gorges, China. Environmental Monitoring and Assessment, 2011, 176(1/2/3/4) : 125-141.

[22] 胡鸿钧,魏印心. 中国淡水藻类: 系统分类及生态. 北京: 科学出版社, 2006 .

[23 ] Hillebrand H, Dürselen CD, Kirschtel D et al. Biovolume calculation for pelagic and benthic microalgae. Journal of Phycology, 1999, 35(2) : 403-424.

[24] 王 䩀, 王 建. 浮游植物的叶绿素含量、生物量、生产量相互换算中的若干问题. 武汉植物学研究, 1984,2(2): 249-258

[25] 孙 军, 刘东艳, 钱树本. 浮游植物生物量研究 I. 浮游植物生物量细胞体积转化法. 海洋学报, 1999,1(2):75-85.

[26] Heip C, Engels P. Comparing species diversity and evenness indices. Journal of the Marine Biological Association of the United Kingdom, 1974, 54(3) : 559-563.

[27] R Development Core Team. R: A language and environment for statistical computing. R Foundation for Statistical Computing, Vienna, Austria, 2008, ISBN 3-900051-07-0, URL http://www. R-project. org. 